\title{
HIÊUU QUẢ VÀ TÁC DƯNG PHỤ CỦA PHÁC Đồ BỐN THUỐC CHỨA BISMUTH TRONG DIÊT TRỪ HELICOBACTER PYLORI LẦN ĐÂUU VÀ LẦN HAI TẠI VIÊTT NAM
}

\author{
Vũ Văn Khiên ${ }^{1}$, Nguyễn Quang Duật ${ }^{2}$, \\ Phạm Hồng Khánh ${ }^{2}$, Trần Thị Huyền Trang ${ }^{1}$
}

\section{TÓM TẮT}

Mục tiêu: Đánh giá hiêu quả và tác dụng phu của phác đồ bốn thuốc chứa bismuth trong diệt trừ Helicobacter pylori lần đâu và lần hai tại Việt Nam. Đối tượng và phương pháp: Đây là một nghiên cứu hồi cứu, tiến cứu và mô tả về kết quả tiệt trừ $H$. pylori bằng phác đồ bốn thuốc chứa bismuth tại Việt Nam. Chúng tôi đã thu thâp được 10 nghiên cứu, với 1.303 bệnh nhân. Trong 1.303 bệnh nhân điều trị bằng phác đồ bốn thuốc chứa bismuth, có 1089 bênh nhân sử dụng lần đâu và 214 bệnh nhân sử dụng lần hai. Tỷ lệ diệt trừ $\mathrm{H}$. pylori được phân tích theo cả hai thông sổ thiết kế nghiên cứu (PP) và ý định điều trị. Kết quả: Tỷ lệ diệt trừ $H$. pylori lần đầu bằng phác đồ bốn thuốc chứa bismuth theo ý định điều trị (ITT) và thiết kế nghiên cứu $(P P)$ tương ứng là $86,6 \%$ và $93,2 \%$. Tỷ lệ diệt trừ $\mathrm{H}$. pylori lần hai bằng phác đồ bốn thuốc chứa bismuth theo ý định điều trị (ITT) và thiết kế nghiên cứu (PP) tương ứng là $87,3 \%$ và $89,9 \%$. Tác dụng không mong muốn khi sử dụng phác đồ bốn thuốc chứa bismuth lần đầu và lần thứ hai tương ứng là: $66,9 \%$ và $58,5 \%$. Tuy nhiên, phân lớn các tác dung phu đều ở mức nhẹ. Kết luận: Phác đồ bốn thuốc chứa bismuth có hiệu quả cao và an toàn trong điều tri diệt trừ $\mathrm{H}$. pylori lần đâu và lần hai

Tü khóa: Helicobacter pylori, per protocol, intention-to-treat

\section{SUMMARY \\ EFFICACY AND SIDE EFFECTS OF BISMUTH QUADRUPLE THERAPY IN THE FIRST-LINE AND SECOND-LINE TREATMENT IN PATIENTS WITH HELICOBACTER PYLORI IN VIETNAM}

Aim: To assess the safety and efficacy of bismuth quadruple therapy as first-line and second-line treatment in patients with Helicobacter pylori in Vietnam. Subject and methods: This was a retrospective, prospective and descriptive study of the results of $\mathrm{H}$. pylori eradication with bismthuth quadruple therapy in Vietnam. The experience consisted of 10 studies with 1.303 patients. In 1303 patients were treated with bismuth quadruple therapy, 1089 patients received the first-line treatment and 214 patients received the second-line treatment. The eradication rate of $\mathrm{H}$. pylori is described both as per

\footnotetext{
${ }^{1}$ Bệnh viện TWQĐ 108

Bềnh viến 103 - Hoc viện Quân y

Chịu trách nhiệm chính: Vũ Văn Khiên

Email: vuvankhien108@yahoo.com.vn

Ngày nhận bài: 9.8.2021

Ngày phản biên khoa hoc: 1.10.2021

Ngày duyệt bài: 12.10.2021
}

protocol (PP) analyses and intention-to-treat (ITT) analyses. Results: The rate of first eradication of $\mathrm{H}$. pylori with bismuth quadruple regimen according to intent to treat (ITT) and study design (PP) was $86.6 \%$ and $93.2 \%$, respectively. The rate of second eradication of $\mathrm{H}$. pylori with bismuth quadruple regimen according to intent to treat (ITT) and study design (PP) was $87.3 \%$ and $89.9 \%$, respectively. Side effects when using bismuth quadruple regimen after the first-line and second-line therapy were $66.9 \%$ and $58.5 \%$, respectively. However, most side effects were mild. Conclusion: Bismuth quadruple regimen is highly effective and safe for the first and second eradication of $\mathrm{H}$. pylori.

Key words: Helicobacter pylori, per protocol, intention-to-treat

\section{I. ĐĂT VẤN ĐỀ}

Helicobacter pylori (H. pylori) là một vi khuẩn gram âm, với tỷ lệ nhiểm trên cộng đồng khoảng $50 \%$ dân số thế giới. Tổ chức Quốc tế nghiên cứu ung thư (IARC) đã xếp $\mathrm{H}$. pylori nằm trong tác nhân số I gây ung thư dạ dày. Do vậy, với những bệnh nhân có bệnh lý dạ dày mạn (viêm dạ dày, loét da dày-tá tràng...) cân phải tiệt trừ $H$. pylori. Tuy nhiên, tỷ lệ diệt trừ $H$. pylori lần đâu (first-line) đã giảm xuống, chỉ đạt khoảng $60-70 \%$ và nguyên nhân chính là tình trạng kháng thuốc của $\mathrm{H}$. pylori, trong đó tỷ lệ kháng clarithromycin và metronidazole chiếm tỷ lệ cao nhất. Gần đây, nhiều quốc gia đã sử dụng phác đồ bốn thuốc chứa bismuth để diệt trừ H. pylori. Phác đồ bốn thuốc chứa bismuth kinh điển bao gồm: thuốc ức chế bơm proton (PPI) + bismuth + metronidazole + tetracycline. Ngày nay, cũng có các phác đồ bốn thuốc chứa bismuth cải biên khác, tùy thuộc kháng sinh được lựa chọn. Đồng thuận Maastricht V (2016) khuyến cáo nên sử dụng phác đồ bốn thuốc chứa bismuth để diệt trừ H. pylori lân đâu và kể cả lần hai cho những khu vực có $H$. pylori kháng clarithromycin > $15 \%$. Đề tài tâp hợp các nghiên cứu trong nước về hiệu quả và tác dụng phụ của phác đồ bốn thuốc chứa bismuth trong diệt trừ $H$. pylori lân đâu và lần hai tại Việt Nam.

\section{II. ĐỐI TƯợNG VÀ PHƯƠNG PHÁP NGHIÊN CứU \\ Đối tượng: Chúng tôi đã tập hợp các nghiên} cứu từ năm 2008 đến năm 2020. Có tổng 10 
nghiên cứu trên 1.303 bệnh nhân, bao gồm: 06 nghiên cứu $(n=1089)$ sử dụng phác đồ bốn thuốc chứa bismuth diêt trừ H. pylori lần đầu và 04 nghiên cứu $(\mathrm{n}=214)$ sử dụng phác đồ bốn thuốc chứa bismuth diệt trừ $\mathrm{H}$. pylori lần hai. Đối tượng gồm những bệnh nhân (viêm dạ dày mạn, loét dạ dày-tá tràng, khó tiêu chức năng) đã được khám lâm sàng, nội soi dạ dày, xét nghiệm H. pylori.

\section{Phương pháp:}

- Tiêu chuẩn lựa chọn diệt trừ $\mathrm{H}$. pylori lần đầu (first-line)

+ Bệnh nhân $\geqq 18$ tuổi

+ Nhiễm $\mathrm{H}$. pylori, xác chẩn bằng mô bệnh học và/hoặc CLO test, hoặc test hơi thở

+ Đồng ý sứ dụng phác đồ bốn thuốc chứa bismuth

- Tiêu chuẩn loại trừ lựa chọn diệt trừ $\mathrm{H}$. pylori lần đầu:

+ Bệnh nhân đã các thuốc: Thuốc ức chế bơm proton, thuốc ức chế thụ thể $H 2$, thuốc chống viêm không steroid (NSAID), hoặc kháng sinh trước đó 04 tuần

+ Tiền sử cắt dạ dày, có bệnh lý khác kèm theo (suy gan, suy thận, xơ gan mất bù...), phụ nữ có thai, dị ứng các thuốc, không tuân thủ uống thuốc
- Tiêu chuẩn lựa chọn diệt trừ H. pylori lần hai

+ Bệnh nhân $\geqq 18$ tuổi

+ Nhiễm H. pylori, xác chẩn bằng mô bệnh học và/hoặc CLO test, hoặc test hơi thở

+ Đã thất bại diệt trừ $\mathrm{H}$. pylori lần đầu bằng phác đồ 3 thuốc hoặc bốn thuốc không chứa bismuth. Bệnh nhân đồng ý sử dụng phác đồ bốn thuốc chứa bismth.

Các thông số cần theo dõi:

+ Xét nhiệm H. pylori: Sau 4 tuần điều trị, tất cả các bệnh nhân được xét nghiệm $\mathrm{H}$. pylori bằng CLO test và/hoặc mô bệnh học, hoặc test hơi thở.

+ Theo dõi các tác dụng phụ sau dùng thuốc

+ Tỷ lệ diệt $\mathrm{H}$. pylori được phân tích qua thiết kế nghiên cứu (per protocol: PP) và theo ý định điêu trị (intention-to-treat: ITT) cho các nghiên cứu.

\section{KẾT QUẢ NGHIÊN CỨU}

1. Đặc điểm bệnh nhân sử dụng phác đồ bốn thuốc chứa bismuth diệt trừ $\mathrm{H}$. pylori lân đâu. Từ năm 2016 đến 2020 có 06 nghiên cứu trình bày về hiệu quả phác đồ bốn thuốc chứa bismuth diệt trừ $\mathrm{H}$. pylori lần đầu. Bảng 1 trình bày đặc điểm của nhóm nghiên cứu.

Bảng 1. Đặc điểm nhóm bệnh nhân nghiên cứu

\begin{tabular}{|c|c|c|c|c|}
\hline Tác giả/năm/n & Phác đ’ô & Tuổi & Nam/nũ & H. pylori \\
\hline $\begin{array}{c}\text { B.C. Nam [1] } \\
(2016) \\
(n=306)\end{array}$ & $\begin{array}{l}\text { Pantoprazole } 20 \mathrm{mg} \times 2 \text { viên/ngày } \\
\text { Bismuth subcitrate } 120 \mathrm{mg} \text { x } 4 \text { viên/ngày } \\
\text { Metronidazole } 500 \mathrm{mg} \times 2 \text { viên/ngày } \\
\text { Tetracycline } 500 \mathrm{mg} \times 4 \text { viên/ngày } \\
\text { (phác đồ: PBMT x } 14 \text { ngày) }\end{array}$ & $42,7 \pm 11,7$ & $221 / 85$ & $\begin{array}{l}\text { Test thơ } \\
\text { (C13 UBT) }\end{array}$ \\
\hline $\begin{array}{c}\text { Đ.N.Q.Huệ [2] } \\
(2016) \\
(n=122)\end{array}$ & $\begin{array}{l}\text { Esomeprazole } 40 \mathrm{mg} \times 2 \text { viên/ngày } \\
\text { Bismuth subcitrate } 120 \mathrm{mg} \text { x } 4 \text { viên/ngày } \\
\text { Metronidazole } 500 \mathrm{mg} \times 2 \text { viên/ngày } \\
\text { Tetracycline } 500 \mathrm{mg} \times 4 \text { viên/ngày } \\
\text { (phác đồ EBMT x } 14 \text { ngày) }\end{array}$ & $38,7 \pm 10,5$ & $70 / 52$ & $\begin{array}{c}\text { CLO test \& } \\
\text { Mô bệnh } \\
\text { học }\end{array}$ \\
\hline $\begin{array}{l}\text { N.T.N. Đoan [3] } \\
(2018) \\
(n=87)\end{array}$ & $\begin{array}{l}\text { Rabeprazole } 20 \mathrm{mg} \text { x } 2 \text { viên/ngày } \\
\text { Bismuth subcitrate } 120 \text { mg x } 4 \text { viên/ngày } \\
\text { Amoxicillin } 500 \text { mg x } 4 \text { viên/ngày } \\
\text { Levofloxacin } 500 \text { mg x } 4 \text { viên/ngày } \\
\text { (phác đồ RBAL x } 14 \text { ngày) }\end{array}$ & $44,1 \pm 12,3$ & $24 / 63$ & $\begin{array}{c}\text { Test thơ } \\
\text { (C13 UBT) }\end{array}$ \\
\hline $\begin{array}{c}\text { T.T.K..Tường [4] } \\
(2020) \\
(n=89)\end{array}$ & $\begin{array}{l}\text { Rabeprazole } 20 \mathrm{mg} \times 2 \text { viên/ngày } \\
\text { Bismuth subcitrate } 120 \text { mg x } 4 \text { viên/ngày } \\
\text { Amoxicillin } 500 \text { mg x } 4 \text { viên/ngày } \\
\text { Levofloxacin } 500 \text { mg x } 4 \text { viên/ngày } \\
\text { (phác đồ RBAL x } 14 \text { ngày) }\end{array}$ & $42,2 \pm 13,2$ & $48 / 41$ & $\begin{array}{c}\text { CLO test } \\
\text { hoặc } \\
\text { test thở } \\
\text { (C13 UBT) }\end{array}$ \\
\hline $\begin{array}{c}\text { K.T.Trang [5] } \\
(2020) \\
(n=233)\end{array}$ & $\begin{array}{c}\text { Esomeprazole } 40 \mathrm{mg} \times 2 \text { viên/ngày } \\
\text { Bismuth subcitrate } 120 \text { mg x } 4 \text { viên/ngày } \\
\text { Tetracycine } 500 \mathrm{mg} \times 4 \text { viên/ngày } \\
\text { Tinidazole } 500 \mathrm{mg} \times 2 \text { viên/ngày } \\
\text { (phác đồ EBTTi x } 14 \text { ngày) }\end{array}$ & $44,6 \pm 13,8$ & $166 / 67$ & $\begin{array}{c}\text { CLO test } \\
\text { hoặc } \\
\text { test thở } \\
\text { (C14 UBT) }\end{array}$ \\
\hline
\end{tabular}




\begin{tabular}{|c|c|c|c|c|}
\hline $\begin{array}{c}\text { T.T.K.Tường [6] } \\
(2020) \\
(n=252)\end{array}$ & $\begin{array}{c}\text { Rabeprazole } 20 \mathrm{mg} \times 2 \text { viên/ngày } \\
\text { Bismuth subcitrate } 120 \mathrm{mg} \times 4 \text { viên/ngày } \\
\text { Metronidazole } 500 \mathrm{mg} \times 3 \text { viên/ngày } \\
\text { Tetracycline } 500 \mathrm{mg} \times 4 \text { viên/ngày } \\
\text { (phác đồ RBMT) }\end{array}$ & $43,2 \pm 12,5$ & $96 / 156$ & $\begin{array}{c}\text { CLO test } \\
\text { hoă̆c } \\
\text { test thở } \\
\text { (C13 UBT) }\end{array}$ \\
\hline \begin{tabular}{c} 
(n= 1089) \\
\hline
\end{tabular} & & & $625 / 464$ & \\
\hline
\end{tabular}

Nhận xét: Phần lớn bệnh nhân ở tuổi trung niên, namnữ: 625/464 $(1,3)$, các phương pháp phát hiện $\mathrm{H}$. pylori bao gồm: CLO test và/hoặc mô bệnh học, test hơi thở (urea breath test: UBT) với C13 hoặc C14. Các phác đồ gồm: PBMT (01), EBMT (01), EBTTi (01), RBMT (01), RBAL (02)

2. Hiệu quả diệt trừ $H$. pylori lân đâu bằng phác đồ bốn thuốc chứa bismuth

Bảng 2. Tỷ lệ diệt trừ H. pylori lần đâu bằng phác đồ bốn thuốc chứa Bismuth

\begin{tabular}{|c|c|c|c|c|c|c|c|}
\hline Phân tích & Nam-cs & Huệ-cs & Đoan-cs & Tường-cs & Trang-cs & Tường-cs & Tổng \\
\hline \multirow{2}{*}{ ITT } & $88,6 \%$ & $79,5 \%$ & $93,1 \%$ & $89,9 \%$ & $86,3 \%$ & $84,1 \%$ & $\mathbf{8 6 , 6 \%}$ \\
& $(271 / 306)$ & $(97 / 122$ & $(81 / 87)$ & $(81 / 89)$ & $(201 / 233)$ & $(212 / 252)$ & $(\mathbf{9 4 3 / 1 0 8 9 )}$ \\
\hline \multirow{2}{*}{ PP } & $92,8 \%$ & $90,6 \%$ & $91,4 \%$ & $92,7 \%$ & $92,7 \%$ & $95,9 \%$ & $\mathbf{9 3 , 2 \%}$ \\
& $(194 / 209)$ & $(97 / 107$ & $(53 / 58)$ & $(76 / 82)$ & $(201 / 217)$ & $(212 / 221)$ & $(\mathbf{8 3 3 / 8 9 4 )}$ \\
\hline
\end{tabular}

Nhận xét: Tỷ lệ diệt trừ $\mathrm{H}$. pylori lần đâu bằng phác đồ bốn thuốc chứa bismuth theo ý định điêu trị (ITT) và theo thiết kế nghiên cứu (PP), tương ứng là: $86,6 \%$ và $93,2 \%$.

3. Tác dụng phụ diệt trừ $H$. pylori lân đâu bằng phác đồ bốn thuốc chứa bismuth

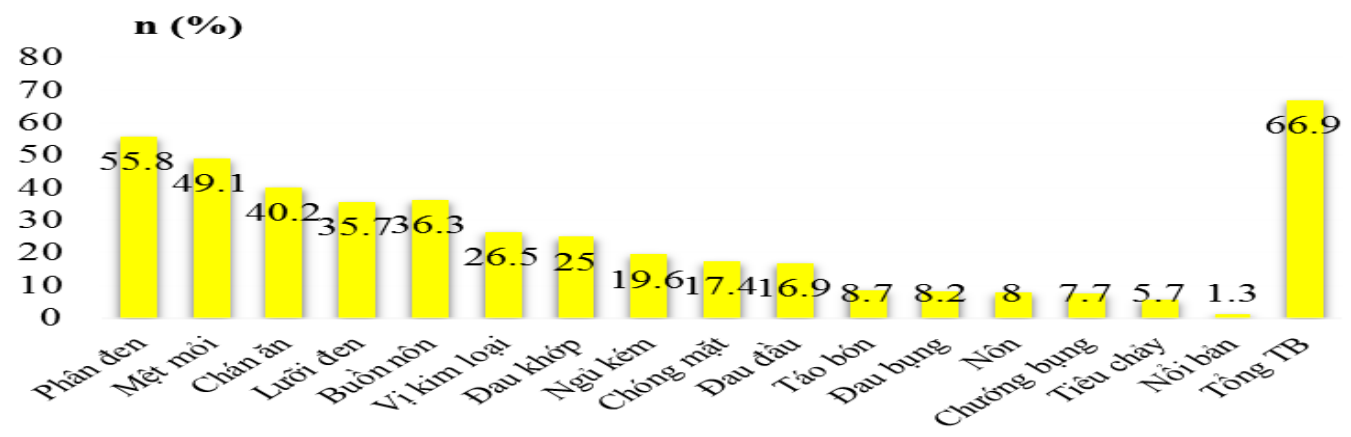

Biểu đồ 1. Tác dụng phụ của phác đồ bốn thuốc chứa bismuth dùng lân đầu

Nhận xét: Tác dụng phụ hay gặp: Phân đen $(55,8 \%)$, mệt mỏi $(49,1 \%)$, chán ăn $(40.2 \%)$... và tỷ lệ chung: $66,9 \%$.

4. Đặc điểm bệnh nhân sử dụng phác đồ bốn thuốc chứa bismuth diệt trừ H. pylori lân hai. Từ năm 2008 đến 2019, có 04 nghiên cứu trình bày về hiệu quả phác đồ bốn thuốc chứa bismuth diệt trừ $\mathrm{H}$. pylori lần hai. Bảng 3 trình bày đặc điểm của nhóm nghiên cứu.

Bảng 3. Đặc điểm nhóm bệnh nhân nghiên cứu

\begin{tabular}{|c|c|c|c|c|}
\hline Tác giả/năm/n & Phác đồ & Tuối & Nam/nữ & H. pylori \\
\hline $\begin{array}{c}\text { T.T.Trung [7] } \\
(2008) \\
(\mathrm{n}=26)\end{array}$ & $\begin{array}{c}\text { Esomeprazole } 20 \mathrm{mg} \times 2 \text { viên/ngày } \\
\text { Bismuth subcitrate } 120 \mathrm{mg} \times 4 \text { viên/ngày } \\
\text { Metronidazole } 500 \mathrm{mg} \times 2 \text { viên/ngày } \\
\text { Tetracycline } 500 \mathrm{mg} \times 4 \text { viên/ngày } \\
\text { (phác đồ EBMT x } 14 \text { ngày) }\end{array}$ & $41 \pm 14$ & $17 / 9$ & $\begin{array}{l}\text { CLO test \& } \\
\text { mô bệnh học }\end{array}$ \\
\hline $\begin{array}{l}\text { N.T.Vinh [8] } \\
\quad(2011) \\
(n=31)\end{array}$ & $\begin{array}{c}\text { Esomeprazole } 20 \mathrm{mg} \times 2 \text { viên/ngày } \\
\text { Bismuth subcitrate } 120 \mathrm{mg} \times 4 \text { viên/ngày } \\
\text { Metronidazole } 500 \mathrm{mg} \times 2 \text { viên/ngày } \\
\text { Tetracycline } 500 \mathrm{mg} \times 4 \text { viên/ngày } \\
\text { (phác đồ EBMT } \times 14 \text { ngày) }\end{array}$ & $45,3 \pm 12$ & $21 / 10$ & $\begin{array}{l}\text { CLO test \& } \\
\text { mô bệnh học }\end{array}$ \\
\hline $\begin{array}{c}\text { Đ.N.Q.Huê [2] } \\
(2016) \\
(n=44)\end{array}$ & $\begin{array}{c}\text { Esomeprazole } 40 \mathrm{mg} \times 2 \text { viên/ngày } \\
\text { Bismuth subcitrate } 120 \mathrm{mg} \times 4 \text { viên/ngày } \\
\text { Metronidazole } 500 \mathrm{mg} \times 2 \text { viên/ngày } \\
\text { Tetracycline } 500 \mathrm{mg} \times 4 \text { viên/ngày } \\
\text { (phác đồ EBMT x } 10 \text { ngày) }\end{array}$ & $38,7 \pm 10,5$ & $27 / 17$ & $\begin{array}{l}\text { CLO test \& } \\
\text { mô bệnh } \\
\text { học }\end{array}$ \\
\hline
\end{tabular}




\begin{tabular}{|c|c|c|c|c|}
\hline $\begin{array}{l}\text { T.T.K.Tường } \\
{[9]} \\
(2019) \\
(\mathrm{n}=113)\end{array}$ & $\begin{array}{c}\text { Rabeprazole } 20 \mathrm{mg} \times 2 \text { viên/ngày } \\
\text { Bismuth subcitrate } 120 \mathrm{mg} \times 4 \mathrm{viên} / \mathrm{ngày} \\
\text { Amoxicillin } 500 \mathrm{mg} \times 4 \text { viên/ngày } \\
\text { Levofloxacin } 500 \mathrm{mg} \times 1 \text { viên/day } \\
\text { (phác đồ RBAL x } 14 \text { ngày) }\end{array}$ & $45.5 \pm 17.3$ & $65 / 48$ & $\begin{array}{c}\text { Test thỏ } \\
\text { (C13 UBT) }\end{array}$ \\
\hline$(n=214)$ & & & $130 / 84$ & \\
\hline
\end{tabular}

Nhận xét: Phần lớn bệnh nhân ở tuổi trung niên, namnữ: $130 / 84(1,5)$, các phương pháp phát hiện $\mathrm{H}$. pylori bao gồm: CLO test và/hoặc mô bệnh học, test hơi thở (urea breath test: UBT) với C13. Các phác đồ : EBMT (03), RBAL (01)

5. Hiệu quả diệt trừ H. pylori lân hai bằng phác đồ bốn thuốc chứa bismuth

Bảng 4. Tỷ lệ diệt trừ H. pylori lân hai bằng phác đồ bốn thuốc chứa Bismuth

\begin{tabular}{|c|c|c|c|c|c|}
\hline Phân tích & Trung -cs & Vinh-cs & Huệ-cs & Tường-cs & Tổng \\
\hline ITT & $93,3 \%(24 / 26)$ & $77,4 \%(24 / 31)$ & $84,0 \%(37 / 44)$ & $90,3 \%(102 / 113)$ & $\mathbf{8 7 , 3 \% ( 1 8 7 / 2 1 4 )}$ \\
\hline PP & $95,7 \%(22 / 23)$ & $80,0 \%(24 / 30)$ & $86,0 \%(37 / 43)$ & $93,1 \%(95 / 102$ & $\mathbf{8 9 , 9 \% ( 1 7 8 / 1 9 8 )}$ \\
\hline
\end{tabular}

Nhận xét: Tỷ lệ diệt trừ $\mathrm{H}$. pylori lần hai bằng phác đồ bốn thuốc chứa bismuth theo ý định điều trị (ITT) và theo thiết kế nghiên cứu (PP), tương ứng là: $867,3 \%$ và $89,9 \%$.

\section{Tác dụng phụ diệt trừ H. pylori lân đâu bằng phác đồ bốn thuốc chứa bismuth}

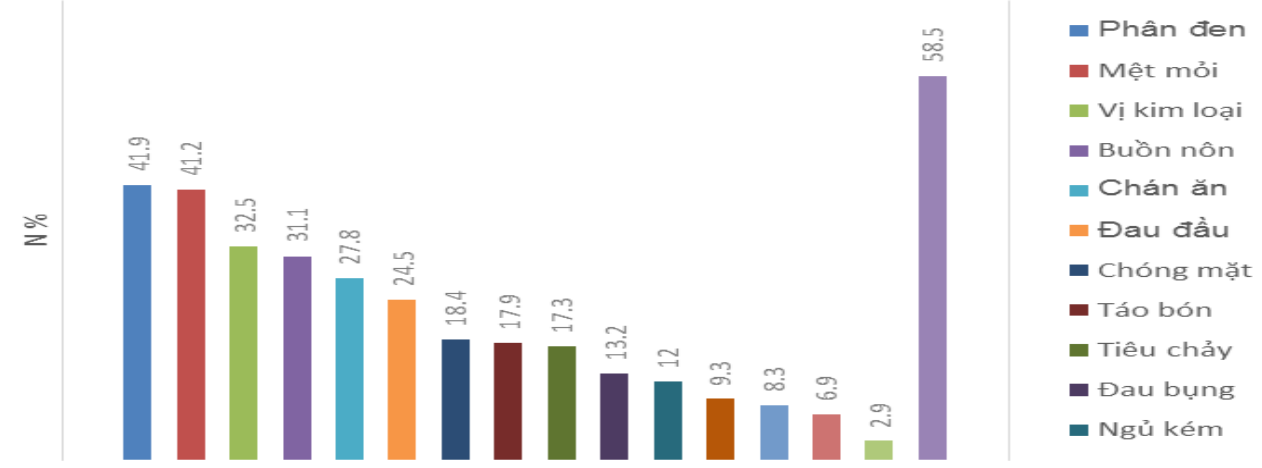

Biểu đồ 2. Tác dụng phụ của phác đồ bốn thuốc chứa bismuth diệt trừ H. pylori lân hai

Nhận xét: Số bệnh nhân có tác dụng hay gặp gồm: Phân đen, mệt mỏi, vị kim loại và buồn nôn.. chiếm tỷ lệ tương ứng: $41,9 \%, 41,2 \%, 32,5 \%, 31,1 \%$.

\section{BÀN LUẬN}

4.1. Bàn về hiệu quả phác đồ bốn thuốc chứa bismuth diệt trừ H. pylori lân đâu. Các nghiên cứu gần đầy tại Việt Nam đã cho thây tình hình kháng thuốc của $H$. pylori đã tăng lên theo thời gian. Tỷ lệ kháng thuốc nguyên phát (primary resistance) của H. pylori với amoxicillin, clarithromycin, metronidazole, levofloxacin, tetracycline và đa kháng tương ứng là: $15,0 \%$, $34,1 \%, 69,4 \%, 27,9 \%, 17,9 \%$ và $48,8 \%$. Do vậy, đồng thuận Maastrictht V (2016), đồng thuận Toronto (2016), hướng dẫn từ đại học Hoa Kỳ (2017) đều khuyến cáo nên sử dụng phác đồ bốn thuốc chứa bismuth cho các khu vực khi $\mathrm{H}$. pylori kháng clarithromycin và metronidazole > 15\%. Do vậy, tại Việt Nam đã sử dụng phác đồ bốn thuốc chứa bismuth để điều trị diệt trị $\mathrm{H}$. pylori lần đầu cho các đối tượng có nhiễm $\mathrm{H}$. pylori như viêm dạ dày mạn, loét dạ dày, loét tá tràng, loét tá tràng có biến chứng chảy máu tiêu hóa và kể cả cho những bệnh nhân khó tiêu chức năng [1-6].

Phác đồ bismuth kinh điển (PPI + bismuth + metronidazol+ tetracycline) đã được sử dụng trên 20 năm để điều trị diệt trừ $H$. pylori. Tuy nhiên, tùy thuộc tình hình kháng thuốc của vi khuẩn $\mathrm{H}$. pylori, kinh nghiệm của thầy thuốc có thể sử dụng các kháng sinh khác nhau như levofloxacin, tinidazole,amoxicilin... và đây được gọi là phác đồ bismuth cải biên (modified bismuth quadruple therapy). Bismth tác động lên H. pylori thông qua đa cơ chế: Diệt vi khuẩn nhờ tạo phức hợp trên thành tế bào và bào tương, ức chế các enzyme của $H$. pylori như: urease, catalase, lipase, photpholipase.. cũng như ức chế sự bám dính của $\mathrm{H}$. pylori, làm giảm tải lượng vi khuẩn $\mathrm{H}$. pylori trong dạ dày

Tập hợp từ 6 nghiên cứu [1-6] sử dụng phác đồ bốn thuốc chứa bismuth trong diệt trừ $\mathrm{H}$. pylori lần đầu (first-line), kết quả trong bảng 2 
cho biết tỷ lệ diệt trừ $\mathrm{H}$. pylori theo ý định điều trị (ITT) và theo thiết kế nghiên cứu (PP) tương ứng là $86,6 \%$ và $93,2 \%$.

Kết qủa nghiên cứu của chúng tôi cũng phù hợp với một số nghiên cứu khác. Tại châu Âu, tỷ lệ kháng thuốc của $\mathrm{H}$. pylori với clarithromycin còn thấp. McNicholl $A G$ và $c S$ nghiên cứu trên 1141 bệnh nhân chưa từng điều trị từ 27 quốc gia tại châu Âu bằng phác đồ bốn thuốc chứa bismuth, cụ thể: thuốc ức chế bơm proton, bismuth (480mg), amoxicillin (2g), claruthromycin $(1 \mathrm{~g})$. Kết quả nghiên cứu cho biết tỷ lệ diệt trừ $\mathrm{H}$. pylori theo ý định điều trị (ITT) và theo thiết kế nghiên cứu (PP) tương ứng là $88,0 \%$ và $94,0 \%$. Những kết quả nghiên cứu này đã cho thấy phác đồ bốn thuốc chứa bismuth chứa các kháng sinh khác nhau (clarithromycin, levofloxacin, tetracycline, metronidazole...) vẫn có hiệu quả cao trong diệt trừ H. pylori lần đầu.

4.2. Bàn về hiệu quả phác đồ bốn thuốc chứa bismuth diệt trừ $H$. pylori lân thứ hai. Đồng thuận Maastricht V (2016) khuyến cáo phác đồ bốn thuốc chứa bismuth, hoặc ba thuốc/bốn thuốc có fluoroquinolone-amoxicillin như là liệu pháp kế tiếp (second-line) cho bệnh nhân đã bị thất bại điều trị lần đầu (first-line). Do vậy, từ năm 2026 đến 2016, đã có 4 nghiên cứu $[2,7-9]$ trình bày về hiệu quả của phác đồ bốn thuốc chứa bismuth trong diệt trừ $\mathrm{H}$. pylori cho những bệnh nhân đã thất bại diệt trừ lần đầu. Kết quả nghiên cứu trong bảng 4 cho biết tỷ lệ diệt trừ $\mathrm{H}$. pylori theo ý định điêu trị (ITT) và theo thiết kế nghiên cứu (PP) tương ứng là $87,3 \%$ và $89,9 \%$.

Tại Trung Quốc, tỷ lệ kháng thuốc của $\mathrm{H}$. pylori cũng tăng lên sau điều trị lần thứ nhất. Do vậy, phác đồ bốn thuốc chứa bismuth đã được áp dụng cho các bệnh nhân này. Liang $X$ và $c S$ đã thực hiện phác đồ bốn thuốc chứa bismuth với các PPI khác nhau và các kháng sinh khác nhau trên 424 bệnh nhân. Các phác đồ cụ thể như sau: Phác đồ LBTM: lanzoprazole $30 \mathrm{mg},(2$ viên/ngày), bismuth $220 \mathrm{mg}$ (2 viên/ngày), tetracycline $500 \mathrm{mg}$ (4 viên/ngày), metronidazole $400 \mathrm{mg}$ (4viên/ngày); Phác đồ LBTF: Lanzoprazole 30 mg, (2 viên/ngày), bismuth 220 $\mathrm{mg}$ (2viên/ngày), tetracycline $500 \mathrm{mg} \mathrm{(3}$ viên/ngày), furazolidone $100 \mathrm{mg}$ (3 viên/ngày); Phác đồ LBAT: lanzoprazole $30 \mathrm{mg}$, (2 viên/ngày), bismuth $220 \mathrm{mg}$ (2 viên/ngày), amoxicillin $1000 \mathrm{mg} \times 3$ lần/ngày, tetracyclline 500 mg (4 viên/ngày); Phác đồ LBAF: lanzoprazole 30 mg, (2 viên/ngày), bismuth 220 mg (2 viên/ngày), amoxicillin $1000 \mathrm{mg} \times 3$ lần/ngày, furazolidone $100 \mathrm{mg}$ (3 viên/ngày). Kết quả nghiên cứu cho biết tỷ lệ diệt trừ $\mathrm{H}$. pylori theo thiết kế nghiên cứu của tất cả 4 nhóm đều vượt trên $90 \%$. Cụ thể, tỷ lệ diệt trừ $\mathrm{H}$. pylori theo thiết kết nghiển cứu với nhóm: LBTM, LBTF, LBAT và LBAF tương ứng là: $93,1 \%, 96,1 \%$, $94,6 \%$ và $99,0 \%$. Tương tự như vậy, tỳ lệ diệt trừ $\mathrm{H}$. pylori theo ý định nghiên cứu với nhóm: LBTM, LBTF, LBAT và LBAF tương ứng là: $87,9 \%, 91,7 \%, 83,3 \%$ và $95,2 \%$. Kết quả này cũng minh chứng kể cả khi $\mathrm{H}$. pylori đã kháng metronidazole thì phác đồ bốn thuốc chứa bismuth vẫn có hiệu quả diệt $\mathrm{H}$. pylori trên $90 \%$ theo ý định nghiên cứu.

Ngày nay, để phân loại đánh giá mức độ diệt trừ $\mathrm{H}$. pylori, dựa trên kết quả phân tích theo thiết kế nghiên cứu $(\mathrm{PP})$ phân chia thành các mức như sau: Rất tốt $\geqq 95 \%$, tốt $\geqq 90 \%$, kém: 85-89\%, không chấp nhận < 85\%. Trong nghiên cứu của chúng tôi khi dùng phác đồ bốn thuốc chứa bismuth tiêu diệt lần đầu thì tỷ lệ diệt trừ $\mathrm{H}$. pylori trung bình theo thiết kế nghiên cứu đạt 93,2\% (đạt mức tốt). Tuy nhiên, khi sử dụng phác đồ bốn thuốc chứa bismuth lần hai (second-line) thì hiệu quả tiệt trừ $\mathrm{H}$. pylori trung bình theo thiết kế nghiên cứu cũng 89,9\% (vượt 89\%). Vì vậy, phác đồ bốn thuốc chứa bismuth vẫn có hiệu quả diệt trừ $\mathrm{H}$. pylori lần đầu và lần hai.

4.3. Tác dụng phụ của phác đồ bốn thuốc chứa bismuth. Phác đồ bốn thuốc chứa bismuth có hiệu quả cao diệt trừ $\mathrm{H}$. pylori lần đầu và lần hai. Tuy nhiên, hạn chế của phác đồ này là có các tác dụng không mong muốn. Tỷ lệ tác dụng không mong muốn khi sử dụng phác đổ bốn thuốc chứa bismuth lần đầu và lần thứ hai tương ứng là: $66,9 \%$ và $58,5 \%$. Tuy nhiên, phần lớn đều ở mức nhe, không có bênh nhân nào ở mức nặng và bình phục sau 01 tuần. Các tác dụng không mong muốn hay gặp ở hai nhóm gồm: phân màu đen, mệt mỏi, vị kim loại... Nghiên cứu của McNicholl AG và cs tại châu Âu trên 1141 bệnh nhân điều trị lần đầu bằng phác đồ bốn thuốc chứa bismuth cho biết có $36 \%$ số bệnh nhân có tác dụng phụ, trong đó $76 \%$ mức nhẹ, $23 \%$ mức trung bình và chỉ có $0,9 \%$ mức nặng. Thời gian xuất hiện tác dụng phụ trung bình 6,5 ngày. Nghiên cứu của Liang $X$ và cs cho biết có sự khác biệt về tác dụng phụ của các phác đồ khác nhau. Tác dụng phụ gặp nhiều ở phác đồ $\operatorname{LBTM}(33,6 \%)$. Các phác đồ: LBTF, LBAT và LBAF chiếm tỷ lệ thấp hơn, tương ứng là: $17,6 \%, 16,2 \%$ và $19,2 \%$. 


\section{KẾT LUẬN}

1. Tỷ lệ diệt trừ $\mathrm{H}$. pylori lần đầu bằng phác đồ bốn thuốc chứa bismuth theo ý định điều trị (ITT) và thiết kế nghiên cứu (PP) tương ứng là $86,6 \%$ và $93,2 \%$. Tỷ lệ diệt trừ $H$. pylori lần hai bằng phác đồ bốn thuốc chứa bismuth theo ý định điều trị (ITT) và thiết kế nghiên cứu (PP) tương ứng là $87,3 \%$ và $89,9 \%$

2. Tác dụng không mong muốn khi sử dụng phác đồ bốn thuốc chứa bismuth lần đầu và lần thứ hai tương ứng là: $66,9 \%$ và $58,5 \%$. Các tác dụng không mong muốn hay gặp ở hai nhóm gồm: phân màu đen, mệt mỏi, vị kim loại...Tuy nhiên, phần lớn đều nhẹ và bình phục sau 01 tuần dùng thuốc

\section{TÀI LIÊU THAM KHẢO}

1. Bùi Č́ní Nam, Nguyển Thị Cẩm Tú, Phạm Thị Thu Hương và cs. Hiệu quả diệt trừ Helicobacter pylori bằng phác đồ PCA, PTMB, PLA. Tap chí khoa học Tiêu hóa Việt Nam 2016;IX(45): 2851-2854.

2. Đặng Ngọc Qứ Huế, Trấn Văn Huy, Nguyễn Thanh Hải. Viêm dạ dày mạn do Helicobacter pylori: Hiệu quả diệt trừ của phác đồ bốn thuốc chứa bismuth (EBMT). Tap chí khoa học Tiêu hóa Việt Nam 2016; IX(45): 2862-2871.

3. Nguyê̂n Thị Nhã Đoan. Hiêu quả của levofloxacin trong phác đồ bốn thuốc chứa bismth diêt trừ Helicobacter pylori. Tạp chí khoa học Tiêu hóa Việt Nam 2018;IX(53): 3294-3299

4. Tuong TTK. The eradication rate of levofloxacin containing quadruple therapy for the first-line treatment of Helicobacter pylori. Biomedical Journal of Scientific \& Technical Research 2020;27(1): 20494-20496

5. Khúc Thu Trang, Nguyễn Công Long, Vũ Trường Khanh. Hiệu quả của phác đồ bốn thuốc chứa bismuth ở bênh nhân loét hành tá tràng chảy máu có Helicobacter pylori. Tạp chí khoa học Tiêu hóa Việt Nam 2021;IX(6): 3842-384

6. Tuong TTK, Huy HQ, Hong TND, et al. Bismuth quadruple therapy versus levofloxacin triple therapy for first-line Helicobacter pylori eradication treatment: multicenter study. Medical Science 2020;24(104): 2246-2250

7. Trân Thiện Trung, Phạm Văn Tấn, Quách Trọng Đức và cs. Hiệu quả của phác đô EAL và EBMT trong diêt trừ Helicobacter pylori điều trị thất bai lần đâu. Ý học TP Hồ Chí Minh 2009;13(phụ bản số 1): 11-17

8. Nguyễn Thúy Vinh. Đánh giá hiệu quả diệt trừ Helicobacter pylori lần hai bằng phác đô $E A C$ và $d$ EBMT. Tap chí y học thực hành 2011;4: 23-26

9. Trân Thị Khánh Tường. Hiệu quá của phác đồ bốn thuổc có levofloxacin cho bệnh nhân nhiếm Helicobacter pylori thất bại điêu trị lần đâu với phác đồ ba thuốc chuẩn. Tạp chí Y học Việt Nam 2019;473: 185-190

\section{TÁC DỤNG KHÔNG MONG MUỐN CỦA ĐIỀU TRI BƯớC MộT PHÁC Đồ PACLITAXEL - CARBOPLATIN UNG THƯ PHỔI KHÔNG TẾ BÀO NHỎ GIAI ĐOẠN IV Ở' BỆNH NHÂN CAO TUỔI}

\section{TÓM TẮT}

Mục tiêu: Đánh giá các tác dụng không mong muốn của điều trị bước một phác đồ Paclitaxel Carboplatin ung thư phổi không tế bào nhỏ giai đoạn IV ở bệnh nhân cao tuổi tại Bệnh viện Hữu Nghị. Đối tượng và phương pháp nghiên cứu: Nghiên cứu mô tả, phối hợp hồi cứu và tiến cứu 51 bệnh nhân $\geq$ 60 tuối, ung thư phổi không tế bào nhỏ giai đoạn IV được điều trị hoá chất bước môt phác đồ PaclitaxelCarboplatin tại Bệnh viện Hữu Nghị, từ tháng 01/2016 đến tháng $12 / 2020$. Kểt quả: Tỷ lệ giảm BC, BCTT là $25,5 \% ; 37,3 \%$. Trong đó chủ yêu là giảm $B C$ và giảm BCTT đô $1 / 2$ là $19,6 \%$ và $27,4 \%$. Tỷ lệ giảm HST, giảm tiểu cầu là $29,4 \%$ và $13,7 \%$. Tỷ lệ buôn nôn,

\footnotetext{
${ }^{1}$ Bệnh viện Hữu Nghi

${ }^{2}$ Bệnh viện $K$

Chịu trách nhiệm chính: Trân Đình Quang

Email: dinhquang228@gmail.com

Ngày nhận bài: 3.8.2021

Ngày phản biện khoa học: 4.10.2021

Ngày duyệt bài: 14.10.2021
}

Trần Đình Quang ${ }^{1}$, Nguyễn Thị Thái Hòa ${ }^{2}$

nôn là $19,6 \%$ và 9,8\%. Tiêu chảy chiếm tỷ lệ $11,8 \%$. Tỷ lệ rối loạn thần kinh cảm giác ngoại vi, đau xương khớp là $17,6 \%$ và $21,6 \%$. Kêt luận: Tác dụng không mong muốn của phác đồ chủ yếu ở mức độ $1 / 2$, an toàn để áp dụng điều trị cho bệnh nhân cao tuổi.

Tứ khóa: Paclitaxel-Carboplatin, Ung thư phổi không tế bào nhỏ, cao tuổi

\section{SUMMARY}

\section{SIDE-EFFECTS OF FIRST LINE PACLITAXEL - CARBOPLATIN REGIMEN FOR STAGE IV NON- SMALL CELL LUNG CANCER IN OLDER ADULTS}

Objective: EstimateSide-effects of first line Paclitaxel - Carboplatin regimen for stage IV nonsmall cell lung cancer in elderly patientsat Huu Nghi Hospital. Patients and Methods: Retrospective and prospective estimated side effects of 51 patients older than 60 years with stage IV non-small cell lung cancer receiving Paclitaxel-Carboplatin asfirst line chemotherapyat Huu Nghi Hospital from January 2016 to December 2021. Results: Of our 51 patients, the rate of leukopenia,neutropeniawere $25,5 \%$ and $37,3 \%$ respectively. Leukopenia andneutropenia grade $1 / 2$ 